\title{
A revised Tesla Turbine concept for 2-phase applications
}

\author{
L. Talluri ${ }^{1}$, P. Niknam ${ }^{1}$, A. Copeta ${ }^{2}$, M. Amato ${ }^{1}$, P. Iora ${ }^{2}$, S. Uberti ${ }^{2}$, C. Invernizzi ${ }^{2}$, G. Di Marcoberardino ${ }^{2}$, L. Pacini ${ }^{1}$, \\ G. Manfrida ${ }^{i}$ D. Fiaschi ${ }^{i *}$
}

${ }^{1}$ University of Florence, Department of Industrial Engineering, Viale Morgagni 40-44, 50139 Firenze, Italy

${ }^{2}$ University of Brescia, Department of Mechanical and Industrial Engineering, Via Branze 38, 25123 Brescia Italy

\begin{abstract}
The Tesla turbine is an original expander working on the principle of torque transmission by wall shear stress. The principle - demonstrated for air expanders at lab scale - has some attractive features when applied to two-phase expanders: it is suitable for handling limited flow rates (as is the case for machines in the range from $500 \mathrm{~W}$ to $5 \mathrm{~kW}$ ), it can be developed to a reasonable size (rotor of 0.1 to $0.25 \mathrm{~m}$ diameters), with acceptable rotational speeds (which range from 500 to $10000 \mathrm{rpm}$ ). The original concept was revisited, designing it for two-phase operation and considering not only the rotor configuration but the whole machine. The flow model was developed using complete real fluid assumptions including several new concepts such as bladed channels for the stator, labyrinth seals, and a rotating diffuser. Preliminary design sketches are presented, and results discussed and evaluated.
\end{abstract}

\section{Introduction}

In recent years, the public engagement towards a sustainable energy production has rushed many researchers, industries, and energy suppliers to search for new ways of producing and recovery energy in an ecological way. This kind of solution needs to be efficient, clean, and effective, reducing the need for primary energy production. These requirements pointed the way to the development of new technologies, the increase of efficiency of the already existing ones, and to the exploitation of wasted streams of energy.

The recovery of an energy stream can be obtained from a system both internally and externally. The external recovery usually deals with waste heat flows, such as combustion gases or hot streams in industrial processes. Internal recovery, on the other hand, is attractive for inverse cycle technologies, such as heat pump or refrigeration cycles. A practicable solution to recover the wasted energy stream in an inverse cycle is by replacing the throttling valve with an expansion device [1].

Within this framework, the importance of developing efficient expanders is of paramount importance, as they could find applications not only in the inverse cycle market but also in the market of power cycles based on trilateral systems [2], which are very fitted for the recovery of low-temperature streams with variable specific heat.
Moreover, inverse cycles and particularly the heat pumps market has been growing steadily in the last years, as a result of the improvement derived by the airsourced heat pumps, which are considered as a renewable technology [3]. However, a challenging point for the further development of more efficient heat pumps is the very difficult task of recovery of the internal stream, as the actual expanders often do not combine the requirements of low cost, efficient and reliable.

Actual expanders for throttling energy recovery are divided into two main categories: velocity type (turbines) and volumetric type (rotary vane, piston, screw, and scroll expanders). For medium and low power systems, especially when working with 2 phase fluids, the volumetric expanders are commonly the best solution. Indeed, velocity type expanders are hindered by several dynamic issues due to the requirement for very high rotational speeds and the large volumetric difference between the two phases [4].

The Tesla turbine, with its relatively simple structure, could become a possible candidate for 2 phase expansion devices, which could find its market in the low power range $(500 \mathrm{~W}-5 \mathrm{~kW})$.

\subsection{Tesla Turbine}

The Tesla turbine is a viscous turbine, which working principle is based on the power conversion

* Corresponding author: daniele.fiaschi@unifi.it 
from the balance of the friction forces at the walls and the exchange of momentum.

The turbine concept was exposed for the first time at the beginning of the last century when Tesla registered a patent for the expander in 1913 [5].

The main trait of the turbine is the absence of blades, which characterize the rotor configuration and the working behavior. The rotor is therefore bladeless and is composed of several staked disks with a very small gap between them. Indeed, the gap between the disks is a fundamental design parameter for this expander, as its dimension strongly affects the performance. Very tight gaps are necessary in order to reach desirable rotor-only efficiencies (75-90\%) [6].

After the pioneer Tesla work, it was W. Rice and his research group in the 60s and 70s of the last century who further studied and developed this expander. Particularly, they both developed an advanced numerical model of the flow within the rotor of a Tesla turbine and performed a full set of experimental investigations on six different turbine configurations. The working fluid analyzed was air and also assessed that the main component responsible for the drop in the total efficiency was the nozzle.

More recently, quite a number of studies have been released on the Tesla turbine, both involving numerical simulations [7, 8] and experimental test campaigns [9]. The majority of the numerical simulations consider the working fluid as incompressible $[5,8]$, only recently some studies are starting to consider the real fluid behavior $[10,11]$. In experimental test campaigns, the working fluids are generally air or water [12, 13], but in recent times, a new assessment on organic fluids are advancing. Indeed, only recently the Tesla turbine has been considered as a suitable expander for ORC $[14,15]$ and it is even more innovative the application of this turbine in 2-phase operation.

In the last year, a few research papers have been published, reporting the development of an innovative test rig for the characterization of the flow within a 2phase Tesla turbine [16], the possible benefits of utilizing a Tesla turbine instead of an expansion valve within a high-efficiency HVAC system [17], or for the energy harvesting when replacing the expansion valves in high-pressure natural gas pipelines $[18,19]$.

The aims of this study are (i) to present a preliminary mathematical model of the Tesla 2-phase rotor and (ii) to introduce a reliable design of the expander so that it can be easily adapted to the specific application.

\section{Flow modeling}

The flow modeling was centred on two components of the turbine, the stator and rotor.

\subsection{Stator Flow}

The stator modeling is of paramount importance when dealing with Tesla turbines, as it is the component that introduces the highest losses within the turbine, as recognized by [20]. The assessed stator is composed by 4 nozzles for each stator disk. The nozzles are curved, starting with a radial inlet and an exit which is almost tangential to the rotor inlet, in order to provide the right flow direction. The design was carried out from a standard approach derived from radial turboexpanders vaned stator [21], modified with partial admission in order to deal with considerably reduced flow rates, as was the case for the single-phase ORC nozzle [22, 23].

The flow model considers the working fluid as a real fluid; thermodynamic properties are evaluated locally depending on the local variables (for example quality and pressure), at present using the Engineering Equation Solver library data [24].

Differently from the single-phase expansion, it is necessary to define a formula for the calculation of the viscosity and sound speed of the flow in 2-phase conditions. Equations 1 and 2 have been implemented in the code, as suggested by [25].

The iterative design process, which was utilized for the single-phase design [23] has been kept: the output of the process is two-loss coefficients, $\zeta_{\mathrm{D}}$ and $\zeta_{\mathrm{R}}$, whose values are equaled iteratively until convergence is reached for a given geometry.

$$
\begin{aligned}
& \mu_{T P} \\
& =\frac{1}{2}\left[\mu_{l} \frac{2 \mu_{l}+\mu_{g}-2\left(\mu_{l}-\mu_{g}\right) x}{2 \mu_{l}+\mu_{g}+\left(\mu_{l}-\mu_{g}\right) x}\right. \\
& \left.+\mu_{g} \frac{2 \mu_{g}+\mu_{l}-2\left(\mu_{g}-\mu_{l}\right)(1-x)}{2 \mu_{g}+\mu_{l}+\left(\mu_{g}-\mu_{l}\right)(1-x)}\right] \\
S S_{T P} & =\left[\frac{\varepsilon}{S S_{g}^{2}}+\frac{(1-\varepsilon)^{2}}{S S_{l}^{2}}+\varepsilon(1-\varepsilon) \frac{\varrho_{l}}{1.35 p}\right]^{-0.5}
\end{aligned}
$$

\subsection{Rotor Flow}

An innovative feature of the present work is the development of a simple model for the evaluation of the flow within a Tesla turbine in 2-phase conditions.

In order to develop a sound analytical model, the following assumptions have been made:

a) Steady flow regime;

b) The viscous force is treated as a body force acting on the flow at each $(r-\theta)$ position;

c) Two-dimensional flow:

- $V_{z}=0$

- $\mathrm{V}_{\mathrm{r}}=$ constant across the channel

- $\mathrm{V}_{\theta}=$ constant across the channel

d) Radial symmetric flow field, uniform at the inlet ( $\mathrm{r}$ $=r_{0}$ ). The flow field is thus the same for any $\theta$, therefore the derivative $\partial / \partial \theta=0$ for all flow variables;

e) $(\partial \mathrm{p} / \partial \theta)$ negligible compared to wall friction forces

Taking into account the previous assumptions, the fundamental Navier-Stokes equations in cylindrical coordinates are reduced to:

Continuity 


$$
\begin{aligned}
& \frac{1}{r} \frac{\partial\left(r \rho_{T P} V_{r, T P}\right)}{\partial r}=0 \quad r \rho_{T P} V_{r, T P}= \\
& \text { cost }
\end{aligned}
$$

Momentum, r-direction

$$
\begin{aligned}
& V_{r, T P} \frac{\partial V_{r, T P}}{\partial r}-\frac{V_{\theta, T P}^{2}}{r}=-\frac{1}{\rho_{T P}}\left(\frac{\partial p}{\partial r}\right)_{T P}+ \\
& f_{r, T P}
\end{aligned}
$$

Momentum, $\theta$-direction

$$
V_{r, T P} \frac{\partial V_{\theta, T P}}{\partial r}+\frac{V_{r, T P} V_{\theta, T P}}{r}=f_{\theta, T P}
$$

Momentum, z-direction

$$
-\frac{1}{\rho_{T P}}\left(\frac{\partial p}{\partial z}\right)_{T P}=0
$$

Knowing the mass flow rate inside each channel, it follows that locally:

$$
V_{r, T P}=-\frac{\dot{m_{t o t}}}{2 \pi r b \rho_{T P}}
$$

The two-phase homogeneous model $\left(w_{l}=w_{g}=w\right)$ $[26,27]$ has been implemented within the code in order to compute the flow field of a 2 phase Tesla turbine; the shear stress can therefore be written as (8).

$$
\begin{aligned}
& \tau_{w}=\frac{f_{T P} \rho_{T P}}{2} w^{2}=\frac{f_{T P} \rho_{T P}}{2}\left[\left(V_{\theta}-\right.\right. \\
& \left.\omega r)^{2}+V_{r}^{2}\right]
\end{aligned}
$$

The friction factor can be computed through Churchill correlation (8).

$$
f_{T P=} 2\left[\left(\frac{8}{R e_{T P}}\right)^{12}+\frac{1}{(A+B)^{3 / 2}}\right]^{1 / 12}
$$

Following then the same procedure highlighted for single phase flow in [11], it is possible to obtain the pressure gradient in radial direction (10), and the tangential velocity (11).

$$
\begin{aligned}
& \left(\frac{\partial p}{\partial r}\right)_{T P}=\frac{\rho_{T P} V_{\theta}^{2}}{r}+\frac{\rho_{T P} V_{r}^{2}}{r}+\frac{2 \rho_{T P} f_{T P}}{D_{h}} * \\
& \sqrt{\left[\left(V_{\theta}-\omega r\right)^{2}+V_{r}^{2}\right]} * V_{r} \\
& \left(\frac{\partial V_{\theta}}{\partial r}\right)_{T P}=-\frac{2 f_{T P}}{D_{h}} * \frac{\left(V_{\theta}-\omega r\right)}{V_{r}} * \\
& \sqrt{\left(V_{\theta}-\omega r\right)^{2}+V_{r}^{2}}-\frac{V_{\theta}}{r}
\end{aligned}
$$

\section{Working fluid assessment}

Once the code has been developed, a parametric assessment was carried out in order to investigate the possibility of developing an innovative 2-phase Tesla prototype. The working fluid selected for the dimensioning of the expander is the refrigerant $\mathrm{R} 1234 \mathrm{ze}(\mathrm{E})$, which is a new generation HFO that will gradually substitute the widespread fluid R134a, due to its low GPW (=7) and nil ODP.

The first parameters which have been analyzed are the rotor diameter ratio and the rotor external diameter.
Figure 1a displays the variation of power per single channel, as a function of rotor inlet diameter and rotor diameter ratio, for a gap between the disks of $0.1 \mathrm{~mm}$, a channel mass flow rate of $0.0125 \mathrm{~kg} / \mathrm{s}$, a total inlet pressure of $997.4[\mathrm{kPa}]$ in saturated liquid condition. The same analysis has been carried out with a gap width of $1 \mathrm{~mm}$ and shown in Fig. 1b. From the analysis, it is shown that higher rotor diameter slightly provides an increase in power generation, while choosing the right rotor diameter ratio is of paramount importance. Particularly, low diameter ratio values allow a better power conversion within the turbine. Even if the rotor diameter slightly affects power production, it is of fundamental importance when selecting the operating rotational speed. Indeed, higher rotor diameters allow selecting lower rotor speed velocities. This is connected to providing the right match between inlet tangential velocity and rotational speed, as indicated in [28].
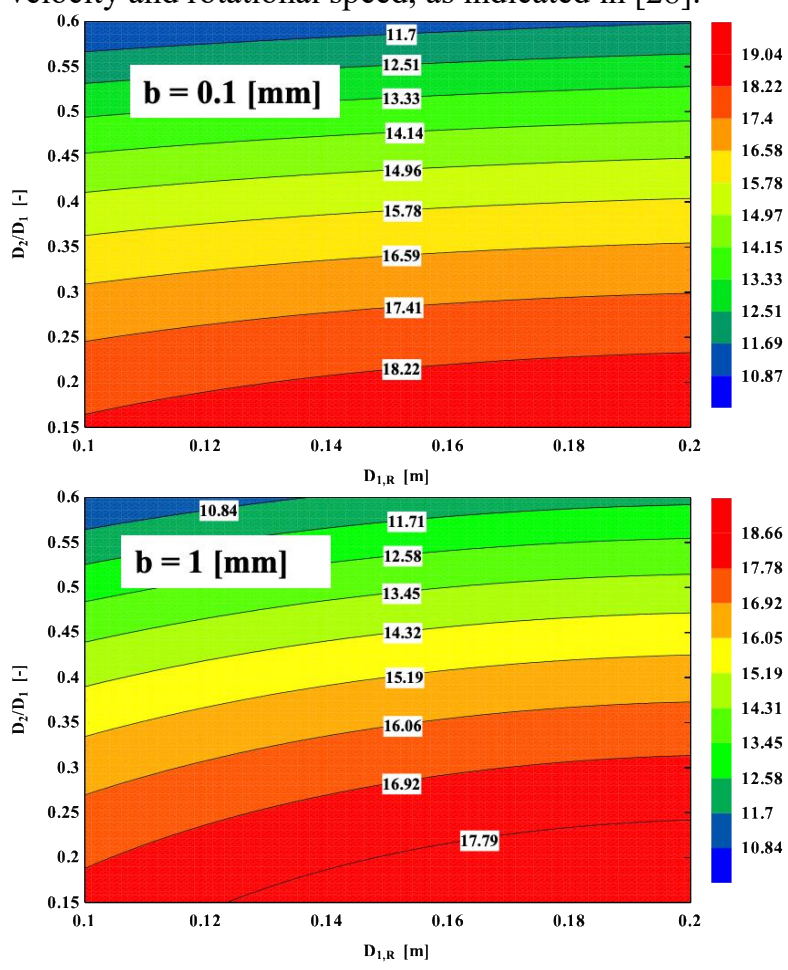

Fig. 1. Power per channel $[\mathrm{W}]$ vs inlet rotor diameter and rotor diameter ratio for (a) $0.1[\mathrm{~mm}]$ channel width and (b) 1 $[\mathrm{mm}]$ channel width.

In order to reduce the leakage flow around the rotor, which will lead to blockage, windage, and pumping losses [29], the highest gap $(1 \mathrm{~mm})$ is selected to perform the other performance analyses. Indeed, selecting a wider rotor channel gap allows establishing a preferential flow path for the fluid (the gap between the rotor and the carter is in the order of $0.1 \mathrm{~mm}$ ).

Figure 2 is therefore obtained for the same total conditions and mass flow rate of the analysis showed in Fig. 1, with a gap of $1 \mathrm{~mm}$, a rotor diameter ratio of 0.2 , and a rotor inlet diameter of $0.2 \mathrm{~m}$. As expected, the power of the channel increases with Mach number and rotational speed. It is interesting to note that the parameter which mostly affects power production is the inlet Mach number. Indeed, high Mach number implies high velocities, which consequently results in higher power conversion, as implied by the Euler equation. 
Figure 3 displays the power par channel production as a function of total mass flow rate (considering 10 rotor channels) and rotational speed, for a Mach number of 0.6. As for the previous case, the highest power production is obtained for a higher mass flow rate and rotational speed. Of particular interest is the very high increase of power with total mass flow rate even at relatively low rotational speeds.

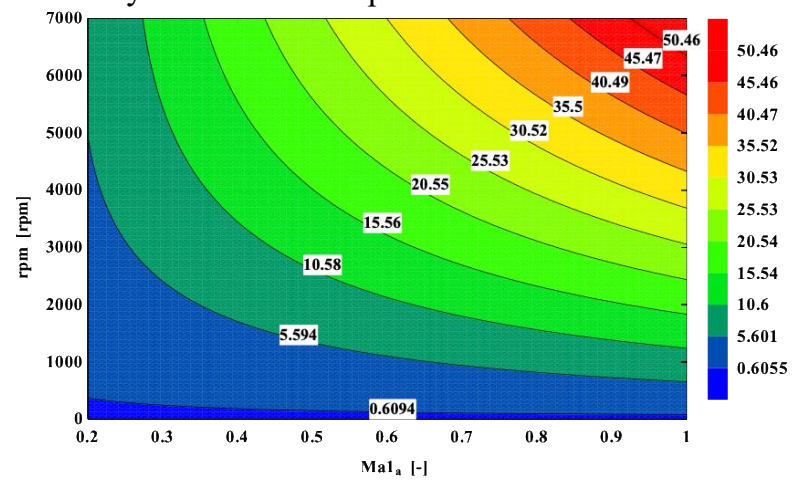

Fig. 2. Power par channel [W] vs rotor inlet Mach number and rotational speed.

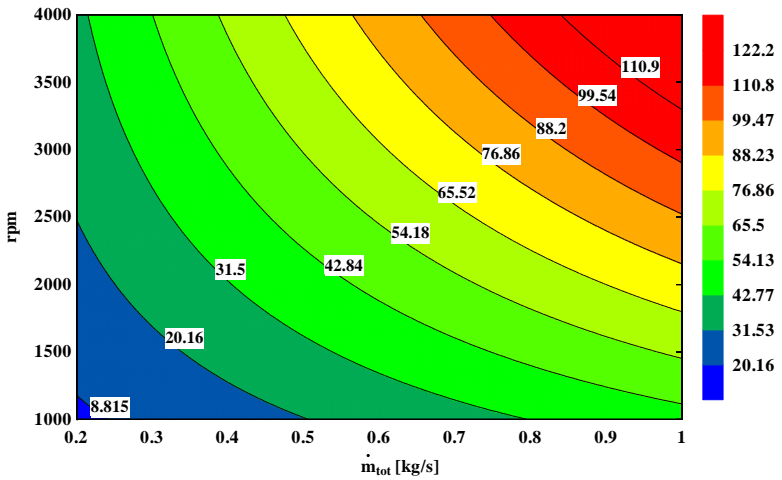

Fig. 3. Power par channel [W] vs total mass flow rate and rotational speed.

\section{Prototype Design}

From the performed parametric analyses it was possible to individuate the right dimensions for the prototype, which is supposed to be tested at the University of Florence test bench [30].

In the presented design, the external carter, which is divided into 2 in order to allow an easy assembly, composes the plenum chamber, which guarantees a correct flow distribution at a limited number (typically, 2 to 4) of radial nozzle inlets (fig. 4). The employed design of the expander configures the stator as several stacked disks with machined nozzles. Each stator disks provided the mass flow rate to a specific rotor disk.

An axial section of the machine is shown in figure 5, displaying the feasibility of modular arrangement, changing the numbers of the stator and rotor disks. The mechanical configuration is a sound double-supported shaft, with one bearing for each side of the expander.

An improved feature of this expander compared to the one developed for single-phase operation is the more complex labyrinth sealing systems which have been designed in order to guarantee that no (or a very limited amount) flow passes around the rotor. This guarantees the reduction or even the absence of blockage, windage, and pumping losses. Furthermore, a slot for a sliding sealing has been also considered, in case the labyrinth sealing would not allow complete blockage of the leakage flow, as shown in Fig. 6.

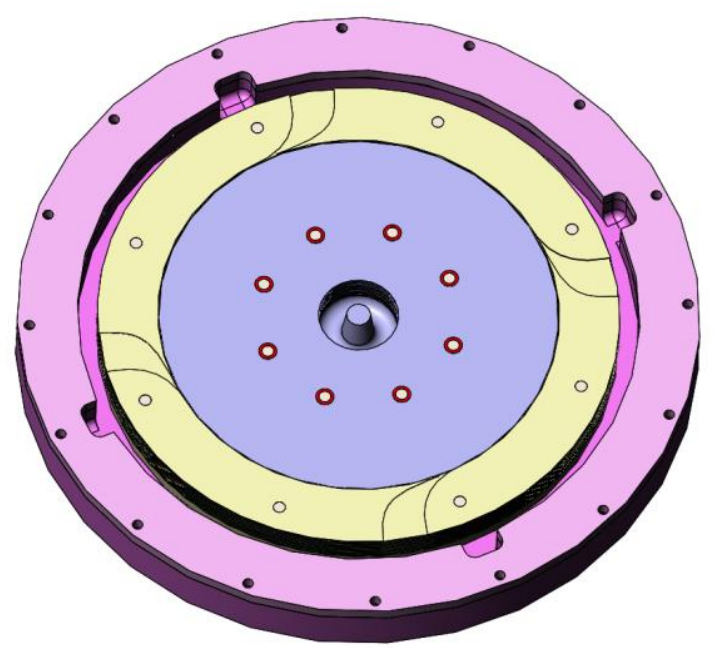

Fig. 4. Plenum chamber and nozzles configuration

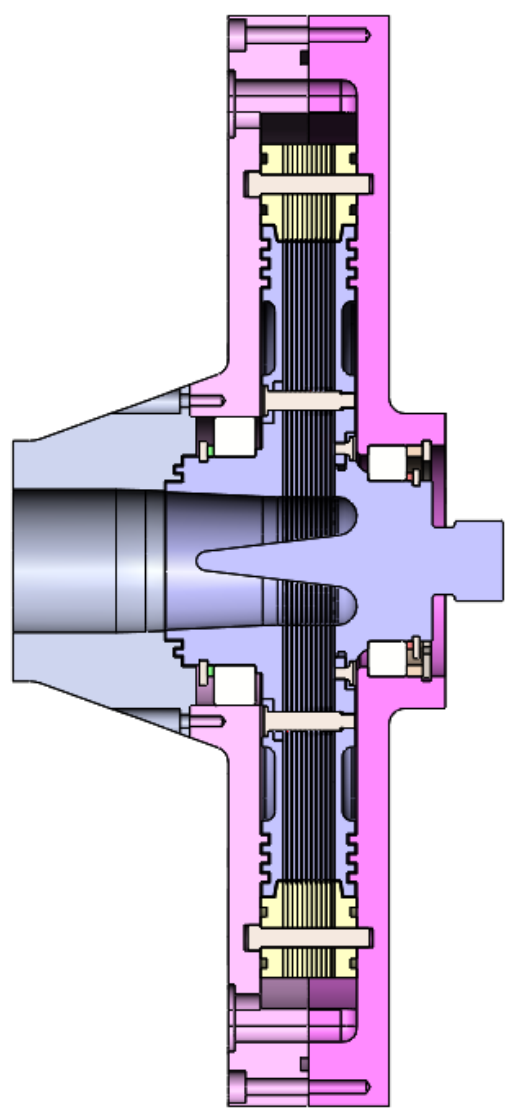

Fig. 5. Axial section of the proposed 2-phase Tesla turbine 


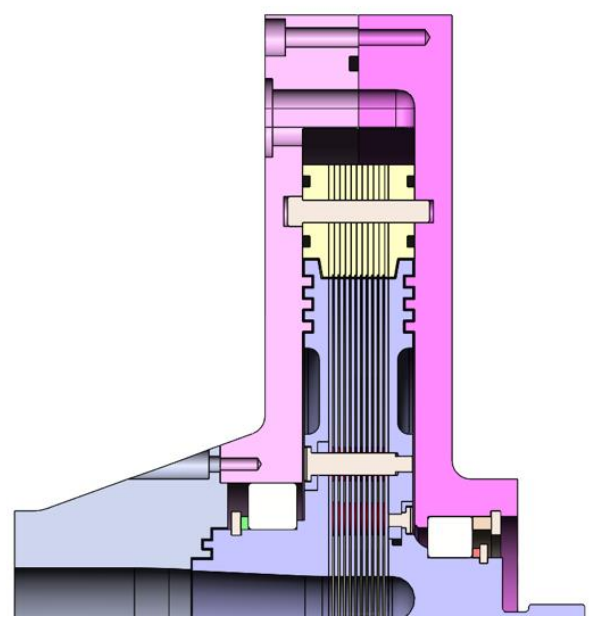

Fig. 6. Enlargement of sealing configurations, labyrinth and sliding.

The last original trait of the proposed design is the introduction of a diffuser at the exit of the rotor. The introduction of such a component, allows the recovery of the kinetic energy in pressure, increasing the turbine efficiency. Figure 7 highlights the proposed configuration of the diffuser and, finally, Table 1 resumes the main dimension of the depicted prototype.

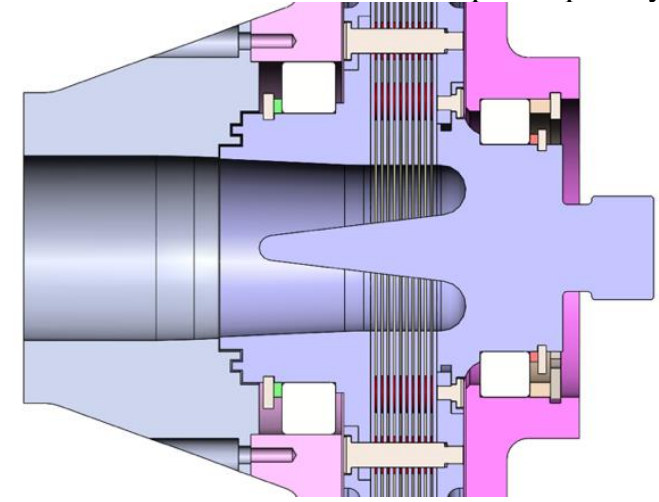

Fig. 7. Enlargement of diffuser section.

Table 1. 2-phase Tesla turbine geometry

\begin{tabular}{lcc}
\hline Parameter & Value & Unit \\
\hline Stator inlet diameter & 0.25 & {$[\mathrm{~m}]$} \\
Stator outlet diameter & 0.201 & {$[\mathrm{~m}]$} \\
Number of stator channels & 2 & {$[-]$} \\
Inlet Stator angle (radial direction) & 0 & {$\left[^{\circ}\right]$} \\
Outlet Stator angle (radial direction) & 87 & {$\left[^{\circ}\right]$} \\
Stator Vane Height & 0.001 & {$[\mathrm{~m}]$} \\
Rotor inlet diameter & 0.2 & {$[\mathrm{~m}]$} \\
Rotor outlet diameter & 0.04 & {$[\mathrm{~m}]$} \\
Channel Height & 0.001 & {$[\mathrm{~m}]$} \\
Number of rotor channels & 10 & {$[-]$} \\
\hline
\end{tabular}

\section{Conclusions}

An original Tesla turbine design for a 2-phase application was developed in this project. The performance assessment was performed with $\mathrm{R} 1234 \mathrm{ze}(\mathrm{E})$ as a working fluid in order to demonstrate the feasibility of the proposed application with a specific prototype size (rotor diameter $0.2 \mathrm{~m}$ ).
A pivotal point of this research is the conceptual design applied for the design of the 2-phase expanders, which tried to tackle all of the issues encountered in previous experimental studies [29]. The key results may be summarised as follows:

- A novel design concept was introduced, tackling rotor inefficiency issues derived from the leakage flows, through the application of advanced sealing configuration.

- The expected nominal power of the prototype is of $200 \mathrm{~W}$ and the expected rotor efficiency of $70 \%$, for a total mass flow rate of $0.125 \mathrm{~kg} / \mathrm{s}$ and a total of 10 rotor disks. If a higher mass flow rate could be reached (actually limited by the test bench), a higher power production could be obtained.

The results indicate that the Tesla turbine appears potentially competitive with other 2-phase expanders thanks to its simple, adaptable design and to the promising power values obtained.

\section{Acknowledgments}

This research was funded by DIMI (University of Brescia) under the TEC (Tesla Expander Chiller) project.

\section{Nomenclature}

$\begin{array}{ll}\mathrm{f} & \text { friction factor } \\ \mathrm{g} & \text { gas } \\ \mathrm{l} & \text { liquid } \\ \mathrm{m} & \text { Mass flow rate }[\mathrm{kg} / \mathrm{s}] \\ \text { ORC } & \text { Organic Rankine Cycle } \\ \mathrm{p} & \text { Pressure }[\mathrm{Pa}] \\ \mathrm{r} & \text { Radius }[\mathrm{m}] \\ \mathrm{SS} & \text { Sound speed } \\ \mathrm{TP} & \text { 2-phase } \\ \mathrm{u} & \text { Peripheral velocity }[\mathrm{m} / \mathrm{s}] \\ \mathrm{v} & \text { Absolute velocity }[\mathrm{m} / \mathrm{s}] \\ \mathrm{w} & \text { Relative velocity }[\mathrm{m} / \mathrm{s}] \\ \mathrm{x} & \text { Quality } \\ \varepsilon & \text { Void fraction } \\ \theta & \text { tangential } \\ \mu & \text { Dynamic viscosity, }[\mathrm{kg} /(\mathrm{ms})] \\ \rho & \text { density, }\left[\mathrm{kg} / \mathrm{m}^{3}\right] \\ \omega & \text { Rotational Speed }[\mathrm{rad} / \mathrm{s}] \\ \zeta & \text { Loss coefficient }\end{array}$

\section{References}

1. Qiu G., Liu H., Riffat S., Expanders for microCHP systems with organic Rankine cycle, Appl. Therm. Eng, 31 (2011).

2. J. Fischer, Comparison of trilateral cycles and organic Rankine cycles, Energy, 36 (2011).

3. EHPA (European Heat Pump Association) Heat pumps on the rise - time to move to system integration!, http://www.ehpa.org/about/news/article/heat- 
pumps-on-the-rise-time-to-move-to-systemintegration/ (2016), last access June 12, 2020.

4. M. Imran, M. Usman, B.S. Park, D.H. Lee, Volumetric expanders for low grade heat and waste heat recovery applications Renew. Sustain. Energy Rev, 57 (2016).

5. Tesla, N., "Turbine”, U.S. Patent No. 1061 206, 1913.

6. Carey, V.P., “Assessment of Tesla Turbine Performance for Small Scale Rankine Combined Heat and Power Systems", Journal of Eng. for Gas Turbines and Power, Vol. 132, 2010.

7. Carey, V.P., "Computational/Theoretical Modeling of Flow Physics and Transport in Disk Rotor Drag Turbine Expanders for Green Energy Conversion Technologies", Proceedings of theASME 2010 International Mechanical Engineering Congress and Exposition.

8. Guha, A., and Sengupta S., "The fluid dynamics of the rotating flow in a Tesla disc turbine", European Journal of Mechanics B/Fluids, Vol. 37, 2013.

9. Schosser C., Fuchs T., Hain R., Lecheler S., Kahler C., "Three-dimensional particle tracking velocimetry in a Tesla turbine rotor using a nonintrusive calibration method", in: $18^{\text {th }}$ International Symposium on the Application of Laser and Imaging Techniques to Fluid Mechanics, Lisbon, 2016.

10. Manfrida G., Talluri L., "Fluid dynamics assessment of the Tesla turbine rotor", in: Thermal Science, 2019.

11. Talluri L., Fiaschi D., Neri G., Ciappi L., "Design and optimization of a Tesla turbine for ORC applications", in: Appl. Energy, 226, 2018.

12. Renuke A., Traverso A., Pascenti M., "Experimental and computational investigation of Tesla Air Micro-Expanders", in: International Gas Turbine Congress (IGTC), Tokyo, 2019.

13. Peshlakai A, "Challenging the Versatility of the Tesla Turbine: Working Fluid Variations and Turbine Performance", M.S. Thesis, Arizona State University, 2012.

14. Song J., Gu C.W., Li X.S., "Performance estimation of Tesla turbine applied in small scale Organic Rankine Cycle (ORC) system", in: Appl. Therm. Eng., 110, 2017.

15. Ciappi L., Fiaschi D., Niknam P.H., Talluri L., 2019. Computational investigation of the flow inside a Tesla turbine rotor, Energy, 173: 207-217.

16. Traverso A., Reggio F., Silvestri P., Rizzo S., Engelbrecht G., Chasoglous A., Two-phase flow expansions: development of an innovative test-rig for flow characterization and CFD validation, E3S Web Conf., Vol. 113, (2019), SUPEHR19 Sustainable PolyEnergy generation and HaRvesting.

17. P. Iora, A. Cassago, C. Invernizzi, G. di Marcoberardino, A. Copeta, S. Uberti, D. Fiaschi,
L. Talluri, L.Tribioli, Assessment of Energy Consumption and Range in Electric Vehicles with High Efficiency HVAC Systems Based on the Tesla Expander," SAE Technical Paper 2019-240244, 2019.

18. Sheikhnejad Y., Simoes J., Martins N., Energy harvesting by a novel substitution for expansion valves: special focus on city gate station of highpressure natural gas pipelines, energies, (2020), $12,956$.

19. Sheikhnejad Y., Simoes J., Martins N., Introducing Tesla turbine to enhance energy efficiency of refrigeration cycle, Energy Reports, $6,(2020$.

20. Guha, A., and Smiley, B., "Experiment and analysis for an improved design of the inlet and nozzle in Tesla disc turbines", Proceedings of the Institution of Mechanical Engineers, Part A: Journal of Power and Energy.

21. Fiaschi, D., Innocenti, I., Manfrida, G., Maraschiello, F., "Design of micro radial turboexpanders for ORC power cycles: From 0D to 3D", Applied Thermal Engineering, Vol. 99, 2016.

22. Manfrida G., Pacini L., Talluri L., "A revised Tesla turbine concept for ORC applications", in: Energy Procedia, 129, 2017.

23. Manfrida G., Pacini L., Talluri L., “An upgrade Tesla turbine concept for ORC applications", in: Energy, 158, 2018.

24. Engineering Equation Solver, EES, F-Chart software, Po Box 444042, Madison, WI 53744, www.fchart.com

25. Niknam PH., Fiaschi D., Mortaheb HR., Mokhtarani, An improved formulation for speed of sound in two-phase systems and development of 1D model for supersonic nozzles, Fluid Phase Equilibria, 446, (2017).

26. Awad MM., Muzychka YS., Two-phase flow modeling in microchannels and minichannels, Heat Transfer Engineering, 31, (2010).

27. Li X., Hibiki T., Frictional pressure drop correlation for two-phase flows in mini and micro multi channels, App. Thermal Eng., 16, (2017).

28. Talluri L., Dumont O., Manfrida G., Lemort V., Fiaschi D., "Geometry and performance assessment of Tesla turbines for ORC", in: Proceedings of ORC2019, $5^{\text {th }}$ International Seminar on ORC Power Systems, September 9-11, 2019, Athens, Greece.

29. Talluri L., Dumont O., Manfrida G., Lemort V., Fiaschi D., Experimental investigation of an Organic Rankine Cycle Tesla turbine working with R1233zd(E), Applied Thermal Engineering, 174, 2020.

30. Galoppi G., Ferrari L., Ferrara G., Fiaschi D., Development and characterization of a compact rig to test expanders for superheated and saturated organic fluids, En. Conv. And Man., (2019). 